\title{
NITRATE POLLUTION RISK ASSESSMENT: FROM THE MODEL TO THE INDICATOR
}

\author{
A. LACROIX ${ }^{1}$, F. LAURENT $^{2}$, D. RUELlAND ${ }^{3}$, E. SAUBOUA ${ }^{4}$
}

\begin{abstract}
The diffuse nature of nitrate pollution makes it difficult to evaluate existing or planned measures to reduce it. Tools have therefore been developed to assess this pollution, ranging from simple indicators to complex models. The aim of this paper is to compare indicators and models by analysing results obtained from their individual application to the same area. The pros and cons of each approach are evaluated in terms of both the conditions of their implementation and the results obtained. This comparison helps to guide the choice of a methodology. Rules governing that choice are set in relation to the nature of the diagnosis to perform and the characteristics of the area under study.
\end{abstract}

\section{INTRODUCTION}

Nitrate pollution is a threat to many of Europe's water resources, particularly in north-western France. Some sources of drinking water have been abandoned as they no longer meet the required standards. It is common knowledge that agriculture is the cause of most of this pollution. However, due to the diffuse nature of the pollution, emissions cannot be imputed with any precision, neither in space nor in time. This makes it difficult to evaluate current or planned measures to reduce them. Tools representing emission and nitrate transfer processes, ranging from simple indicators to more complex models, have therefore been developed.

Agri-hydrological simulation models allow precise understanding and representation of nitrate pollution processes resulting from agricultural activity. The realism of this type of analysis can, moreover, be validated by comparison with field measurements. However, these models,

\footnotetext{
${ }^{1}$ Laboratoire GAEL, UMR INRA-Université Pierre Mendès France, BP 4738040 Grenoble Cedex 09 France. Fax number : 33 (0)4 768254 55. e-mail : $\underline{\text { lacroix@grenoble.inra.fr }}$

${ }^{2}$ UMR ESO CNRS - Université du Maine, avenue Olivier Messiaen, 72085 Le Mans cedex 09 France. Fax number : 33 (0) 2-43-83-38-84. e-mail : flaurent@univ-lemans.fr

${ }^{3}$ CNRS, UMR HydroSciences - Maison des Sciences de l'Eau, Université Montpellier II, 34095 Montpellier cedex 5 France. Fax number : 33 (0)4 671447 74. email : ruelland@msem.univ -montp2.fr

${ }^{4}$ Unité INRA PSDR, BP 4738040 Grenoble Cedex 09 France. Fax number : 33 (0)4 7682 54 55. e-mail : sauboua@ grenoble.inra.fr
} 
usually necessitating a large amount of data and expertise, cannot be implemented by decision-makers. Indicators have therefore been developed to alleviate these difficulties and to introduce decision support tools. They are based on a simplified formalism and easily accessible data. The ir reliability is nevertheless debatable since it is difficult to validate them by pollution measurement.

The aim of this paper is to compare models and indicators by analysing results obtained from their individual application to the same area. More precisely, it is to evaluate the pros and cons of each approach in terms of both the conditions of their implementation and the results obtained, and to compare the effects of the spatio-temporal resolution of the data and the choice of formalism inherent in each tool. Section 1 examines the conception of different indicators and models as given in the literature. Section 2 presents the model and the indicator selected here, as well as the case to which they are applied. Section 3 concerns the results obtained, and Section 4 considers the conditions of use of each of these tools.

\section{INDICATORS AND MODELS IN THE LITERATURE}

Although simulation models have been and still are widely published, interest in indicators is more recent, dating only from the mid-nineties. In fact, their development is an outcome of the issue of sustainable agriculture. In this perspective, policy-makers (the State, environmental agencies, professional actors, etc.) have to choose between different pollutionabatement measures and must therefore be able to assess their mid- and long-term effects. Indicators should enable them to perform diagnoses on wide areas by mobilising commonlyknown data, and to check the extent to which the new objectives assigned to agriculture are being achieved.

\section{Indicators}

With the perspective of identifying the means by which States are able to define and implement policies for sustainable agriculture at the least cost, the OECD has undertaken the development of indicators covering 13 fields on the agriculturalenvironmental interface: use of nutrients, pesticides and water, land use, quality of the soil and water, biodiversity, etc. (OECD 1997, 1999, 2001; Parris, 1998; Piorr, 2003). This initiative illustrates how important indicators have become to decision-making on environmental issues.

Indicators can be used to present a simple quantitative or qualitative description of complex phenomena or systems. They may be based on agricultural practices (means-based or efforts- 
based) or on the effects of these practices on the environment (effects-based). Moreover, they may be calculated according to different spatio-temporal scales: on the scale of a field or catchment area, or that of a day or year.

Most authors propose indicators for nitrate pollution management that are based on the difference between nitrogen inputs and outputs in the soil system, calculated on an annual basis. The nitrogen balance (Simon and le Corre, 1992) is calculated on a field scale and guides the farmer in the use of fertilisers. At farm level, it can be calculated with the BASCULE method (Balance Azotée Spatialisée des systèmes de CULture de l'Exploitation i.e. spatial nitrogen balance of farm crops) (Benoît, 1992). The nitrogen surpluses method used by the European Environmental Agency is based on simplifying hypotheses and easily accessible data, and is therefore applicable on a variety of scales: field, farm (Chambres d'Agriculture et al., 1998), municipal or catchment area (Crouzet et al., 1999), region (Auckenthaler et al., 1999; Hansen, 2000) or country (Pau Vall and Vidal, 1999). The adaptability of this method explains its successful use.

The calculation of nitrogen surplus is useful in the analysis of agricultural systems but provides no information on their environmental impacts or on trans fers of the surplus towards water sources. The nitrogen index of the AGRO*ECO method (Girardin et al, 1999 and the Merlin index (Aimon-Marie et al., 2001) attempt to compensate by measuring nitrogen leaching below the root zone. These indexes were designed for diagnoses on a field or farm scale. They are difficult to transpose onto the scale of catchment areas, due to the lack of data or their acquisition costs (e.g. concerning the measurement of nitrogen residues for each of the fields concerned) for such a large geographical area.

Elsewhere, qualitative indicators have been used. They do not yield flow values but can grade the risk of pollutant transfer by means of scores derived from multicriteria analysis. This method is suitable for locating problem areas. It has been extensively used to analyse the vulnerability of groundwater (Aller et al., 1987; Burkart et al., 1999 ; Landreau et al. 1999; Vrba and Zoporozec, 1994) and to evaluate nitrogen pollution risks (Berka et al., 2001; Mattikalli and Richards, 1996). It was boosted by the development of Geographic Information Systems (GIS) which have facilitated spatialised multicriteria analysis (Malczewski, 1999).

Van der Werf and Petit (2002) have demonstrated that effects-based indicators are preferable to means-based indicators because they provide information as to which measures will best control pollution. On the other hand, they demand more information than means-based indicators. These authors also note that quantitative indicators are preferable to qualitative 
indicators since i) the scores do not have units of dimension, which makes them difficult to compare with field observations, and ii) the thresholds and weights attributed to each dimension analysed cannot be scientifically defined and are, consequently, somewhat arbitrary.

Finally, Schroder et al. (2004) draw attention to the effects of the various spatio-temporal scales for which the indicators are calculated. In fact, the choice of scale is decisive, for when the basic unit increases, compensation effects may appear between highly polluted areas and those far less polluted, or between peak pollution periods and those of low flow or of pollutant dilution. This statement on the conditions of indicator use also applies to the implementation of simulation models.

\section{Simulation models}

The dividing line between indicators and models is not entirely clear. Indicators are models, to a certain extent, in so far as they are simplified representations of a part of the real world. Yet simulation models have a particular characteristic: they take into account the time dynamics of processes by representing both the temporal variability and the sequence of events. A simulation model therefore implies a time-step: the values taken by variables at any given point in time depend on the values at the preceding points in time.

The literature presents different types of hydrologic models. It is possible to distinguish between lumped and distributed models, depending on whether they refer to a homogenous area or take into account the spatial variability of certain data. Within the range of temporal simulation models, modelling per event (e.g. the effect of heavy rainfall) differs from longterm continuous modelling. Finally, empirical modelling differs from physical modelling in that it features only outputs and does not attempt to represent the phenomena by means of physical laws.

\section{Empirical modelling}

Empirical models sometimes yield very good results in the area for which they were designed. The relationships between inputs and outputs within the system are established solely to reproduce measured outputs. A type of model frequently applied in the field of nonpoint pollution consists of the "exportation coefficients" of nutrients. These coefficients make it possible to link factors such as different types of crop and/or soil, the efficient rainfall depth, 
to the outputs of the catchment area in terms of pollutant flow (Vervier et al., 1999; Wickham et al., 2000; Worrall and Burt,1999).

The main drawback with these models is that they too often operate as "black boxes" since the parameters have little or no measurable reality. The determination of parameters can be undertaken only after calibration in relation to the zone under study and for a given meteorological and land use situation. It is therefore difficult to transpose empirical models onto unmeasured areas. Moreover, the use of such models to test the impact of changes in agricultural practices on the quality of the water has proved to be unsatisfactory. Their use in a situation that contrasts sharply with the one on which they were calibrated (e.g. due to change of climate or farming practices) would require the evaluation of a new set of parameters.

\section{Physically-based models}

The authors of physically-based models aim at representing the processes in question according to physically established laws. This type of model can therefore be used to predetermine parameters by means of measurements of the area under study. After calibration with the spaces measured, the effects of evolving land use and consequently of altered agricultural practices can be simulated. Coupled with GIS (Geographic Information System) at different levels of integration (Loague and Corwin, 1998; Pullar and Springer, 2000; Ruelland, 2004), these models allow the spatialisation of pollutant emission and transfer phenomena. It is thus possible to classify the areas according to their vulnerability or their priority for action.

Physically-based models nevertheless have several limits:

- precision of input data : the quality of results depends on the representation of the spatial variability of the parameters (Merot and Durand, 1997). The large number of calibration variables in many of these models make them sensitive to the propagation of errors since the evaluation errors of each variable build up in the calculations (Beven, 1993; Bierkens et al., 2000). They are therefore difficult to apply to large surfaces for which few measurements are available.

- representation of connections between the different entities of the landscape: they do not adequately take into consideration the effect of areas of retention of pollutants (e.g. humid areas that reduce nitrogen flows). 
- sensitivity to the calibration process: these models have to be calibrated on the basis of long series of measurements of pollution flowing out of catchment areas, including drought years and high rainfall years so that a sufficiently realistic range of sensitivity is included (Carrubba, 2000).

Some physically-based models nevertheless offer interesting results on the scale of large catchment areas, because they have been either specifically designed or adapted. Refsgaard et al. (1999), for example, adapted the MikeShe model to two catchment areas of $500 \mathrm{~km}^{2}$ and obtained well-validated results. The NPSM (Nonpoint Source Pollution Model) has been applied to 1,000 and $2,000 \mathrm{~km}^{2}$ catchment areas in the United States with irregular results (Carruba, 2000). SWAT is another example of the adaptation of these models to large areas.

\section{Indicator / model comparison}

Comparison of indicators and models is rarely found in the literature. Haag and Kaupenjohann (2001) are two of the very few authors to focus on the subject. They criticise models by showing that they could never faithfully render the variability or heterogeneity of processes. These authors recommend switching from impact-oriented to risk-oriented approaches for identifying critical areas. In this respect, methods based on balances and leaching potential provide indicators of (un)sustainable management on the landscape scale. Thus, the integration of simple physical factors (soil, topography and climate) allows the grading of site-specific risks. This approach is oriented not towards the evaluation of environmental impacts but rather towards the prevention of imbalances long before they have been measured.

Rapion and Bordenave (2001) are critical of the use of indicators. They carried out a comparative test on an indicator and a model applied to three small catchment areas in Brittany (France). The indicator in this case is the nitrogen balance and the model is a hydrologic model derived from GLEAMS. The results of the nitrogen balance method do not seem to correlate with output flow records, even though the model produces far more satisfactory results. This can be explained in different ways: i) nitrogen flows below the root zone are determined by the annual surplus as well as by the mineralisation of the organic nitrogen pool and the effects of input from previous years; ii) the amount of nitrogen leaching under a field depends strictly on the amount of mineral nitrogen present in the soil at the beginning of the drainage season and on the volume of drained water; iii) denitrification is an important process in this altered basement complex region. In the subsurface layers of 
cultivated land, denitrification is sufficient to explain the greater part of the difference found between the mineral nitrogen balance and nitrogen flows in streams.

Accordingly, when expressed, opinions on the use of indicators or models are contradictory. We therefore consider it useful to compare the advantages and disadvantages of each of these two tools. For this purpose we have chosen to apply them to a catchment area in the northwest of France.

\section{METHODS AND DATA}

\section{The SWAT model}

SWAT was developed at the USDA Agricultural Research Service (Arnold et al., 1993, 1998, 2000). It was designed to be applied to catchment areas ranging from a few hundred to several thousand square kilometres. This model is semi-distributed: some parameters are distributed whereas others are considered globally. It belongs to the group of agri-hydrologic models since it is intended for the study of agricultural nonpoint source pollution and serves to finely analyse processes linked to soil and vegetation. It serves to estimate flows of nutriments, pesticides and sediments in the soil, groundwater and surface water, as well as water flow. The model allows the calculation of input and output flows. These values are used, in turn, for the calibration and the validation of the model by comparison with measurements. The basic unit for calculation is the HRU (Hydrologic Response Unit) which represents the result of the combination of a type of soil, a type of soil use, and a type of sub-catchment area. Any identical combination of these three features is supposed to produce similar agro-hydrologic behaviour.

SWAT cannot be considered to be an entirely physical model. Despite the modelling of certain phenomena on the basis of acknowledged laws (as in the case of the module for water and nitrogen transfer and storage in the soil, based on the EPIC model), SWAT is to some degree empirical, especially concerning the representation of run-off (curve number method) or groundwater discharge, simplified by empirical parameters such as the base flow coefficient.

This model takes environmental factors into account (soil type, above all) as well as agricultural practices (fertilisers, tillage, irrigation, drainage, etc.) It yields satisfactory validations for numerous catchment areas worldwide (Santhi et al., 2001; Srinivasan et al., 1998; Vache et al., 2002) and its validity has been checked for catchment areas of different 
sizes in diverse geological contexts. Access to variables and parameters is facilitated by combining the model with a GIS. This model allows the follow-up of flows and storage at each stage of the water-cycle. It is possible to analyse both the impact on water resources and the factors determining transfers on different scales (Tripathi et al., 2003). Some outputs of this model, such as pollutant emission, can be spatialised. Moreover, the sensitivity of SWAT in tracing agricultural practice has been verified, particularly by Vache et al. (2002) who have modelled the effects of nonpoint pollution reduction scenarios (optimisation of fertiliser use, strips of vegetation along streams, no-till) on the quality of the water in two catchment areas in Iowa.

The map layers of the soil as well as land use relate to databases with descriptive parameters which can be adapted as necessary. For example, the database for crops gives information on agronomic parameters such as temperatures for plant growth, the heat-units needed to reach maturity, root depth, proportion of dry matter, harvest index, etc. The soil database has measured elements such as texture, depth or hydrologic properties, including hydraulic conductivity, porosity, Available Water Content (AWC) etc. The agricultural practices associated with crops and fields describe dates for sowing, harvesting, grazing, different sorts of nutriment inputs, tillage, residue management, and rotations.

The first step in the implementation of SWAT, like any other hydrologic model, is the adjustment of certain parameters. Their values are adapted to fit the model outputs to the real observations, according to efficiency index statistics (Nash and Suttcliffe, 1970). The results are then validated over another period without any parameter change. Calibration and validation of the parameters primarily concern hydrology (water flow in streams), then agronomic variables (yields) and, finally, nitrogen flows observed in streams and nitrogen storage in the soil.

\section{Polluting Emission Indicator}

As noted above, the nitrogen balance method displays many possibilities. It can be implemented on a wide variety of scales, notably for large areas. But it is also very limited, for it fails to take into account local soil and climatic conditions. Studies have shown that the amounts of nitrogen leached are very loosely linked to excessive nitrogen inputs. Experiments carried out on livestock breeding systems in Europe show that the amount of leached nitrogen accounts for $30 \%$ to $40 \%$ of the surplus in coarse and well-drained soils. This amount is only from $10 \%$ to $20 \%$ in loamy-clayey and poorly drained soils (Le Gall et al., 2000). 
Experiments performed on a small catchment area in Picardy (a region in the north of France) highlight the decisive role of the water recharge in the soil (Mary et al., 1996). Experiments carried out on two small catchment areas in Brittany (France), with different proportions of grass and corn, demonstrate the importance of the length of the intercrop period. Although the nitrogen balances are identical, the nitrate outlet concentration is far less for the catchment area with more grassland (Bordenave et al., 1999).

In other words, in order to establish a relationship between the nitrogen balance and leaching, it is necessary to identify environmental characteristics (soil type, climate conditions) and to take the land use into account. The indicator proposed here, the Polluting Emission Indicator (PEI), includes these factors. It begins with the calculation of the nitrogen surplus and water balance over one year. These annual balances of water and nitrogen are then used to evaluate the risk of nitrogen leaching and the nitrate concentration of the drained water below the root zone.

The nitrogen surplus (i.e. difference between the inputs of organic and mineral nitrogen and the crop requirements) is calculated over one year for the 'commune' (municipal area), according to the model developed by the SCEES, the statistical service of French Agriculture Ministry (Vidal, 1995). Calculation is easy as it is based on: i) variables from simple and easily available positioning data, such as those from the Agricultural Census (land use, size and type of livestock) or from agricultural statistics (yields); ii) parameters describing the crop nitrogen needs, dietary requirements of herbivorous livestock, and nitrogen values of livestock excrement; iii) simplifying hypotheses. It is posited that the net balance between gaseous exchanges is negligible. In other words, atmospheric inputs such as symbiotic nitrogen-fixing by leguminous plants, non-symbiotic nitrogen-fixing by soil micro-organisms, atmospheric deposits and atmospheric outputs such as denitrification and volatisation nearly offset one another. The mineral nitrogen/organic nitrogen transformations in the soil (mineralisation, organisation) are also considered to be balanced.

Drainage is considered to be equal to the annual cumulative surplus of water as calculated by Réménieras' method (1960). The soil water capacity is considered to be at a maximum on 1 January. Monthly calculations of water balances are used to re-evaluate soil water content at the beginning of the following month.

Leaching below the root zone is estimated by means of a function based on the results of experiments in different soils, climates and agricultural conditions. Here the leaching is 
related to the nitrogen surplus, the duration of the intercrop period and the water renewal rate in the soil (ratio of annual drainage to water stored at the field moisture capacity).

Note that the PEI has a number of limits inherent in its design. First, it concerns only the soilplant interface, and fails to inform on water and nitrogen flows beyond the root zone. Second, it evaluates the long-term pollution risk, in that it counts the total nitrogen in the system and not only the leachable mineral nitrogen. Finally, it can assess only steady systems: for example, on the assumption that the soil exchanges are balanced, grassland ploughing cannot be taken into account.

\section{Case Study}

The $385 \mathrm{~km}^{2}$ catchment area of the Moine, devoted mainly to cattle farming, is situated in the north-west of France around the town of Cholet. Geomorphologically, the area consists of a plateau incised by a network of streams with an elevation varying from 180 metres in the north-east to 15 metres in the west.

Geologically, Precambrian and Paleozoïc metamorphic rocks have been affected by the Hercynian tectonics and injected with granite intrusions. The mean annual rainfall at Cholet is $751 \mathrm{~mm}$ and the mean temperature is $11.4^{\circ} \mathrm{C}$ (between 1966 and 1999). This oceanic climate is characterised by fairly regular rainfall throughout the year (maximum in December, with a mean of $80 \mathrm{~mm}$, minimum in July, with a mean of $44 \mathrm{~mm}$ ) and moderate temperatures (monthly mean of $4.9^{\circ} \mathrm{C}$ in January and $18.8^{\circ} \mathrm{C}$ in July). The soil map, on the scale of 1/50,000 (Euriat and Tritz, 2002; Laurent and Rossignol, 2004) shows the dominance of loamy, hydromorphic soils on the plateau, of sandy loam soil on the slopes, and of hydromorphic loamy clay in the bottom of the valleys.

The data used to apply the PEI and the SWAT model are set out in Table 1. Due to differences in the design of these two methods the data may differ, especially as regards their degree of spatio-temporal resolution:

- the basic spatial unit of the PEI calculations is the commune, since this is the smallest unit for which Agricultural Census data are available. SWAT is based on the HRU (Hydrologic Response Units) concept, a homogenous unit in terms of soil and land use;

- the time-step of the PEI calculations is the mean year; SWAT simulates the climate and cultural events on a daily basis. 
It is important to establish whether the differences, due to both the design of these two tools and their spatio-temporal resolution, have an impact on pollution risk assessment in the catchment area under study. The two series of results calculate risks in an agri-climatic context representative of that of the Moine catchment area for the period 1997-2001.

\section{RESULTS}

\section{On the scale of the entire catchment area}

The Polluting Emissions Indicator evaluates the annual mean nitrate concentration of drained water below the root zone at a rate of $71 \mathrm{mg} \mathrm{NO}_{3} / 1$ for the entire catchment area. The SWAT model gives an estimate of $36 \mathrm{mg} \mathrm{NO} / 1$. This discrepancy is due not to the calculation of the drained water depth - 300 and $311 \mathrm{~mm} /$ year for PEI and SWAT, respectively - but rather to calculations of leaching -51 and $26 \mathrm{~kg} \mathrm{~N} / \mathrm{ha} /$ year, respectively. The huge difference in these results can cast serious doubt on the reliability of such evaluations.

Theoretically, the leaching evaluation by SWAT is more reliable than the one by the PEI. SWAT is based on far more detailed representation of the processes occurring upstream from the leaching area (atmospheric fallout, volatilisation, organic nitrogen pool dynamics in the soil, etc.). Moreover, the simulated results are controlled via the calibration phase of the model: the estimated water and nitrogen outlet flows are calibrated according to those of the Roussay measurement station. Over the validation period 2000-2001, a mean simulation of $1,276,000 \mathrm{~kg} \mathrm{~N}-\mathrm{NO} 3$ is obtained, against $1,267,000 \mathrm{kgN}-\mathrm{NO} 3$ for the measurements and a correlation coefficient of 0.60 (Figure 1). Validation requires SWAT not only to simulate leaching under the cultivated zones, but also to take into consideration non-agricultural inputs (such as urban waste water) and the denitrification process. However, as with any simulation model, calibration can give realistic results with erroneous parameter values because of the compensation effect. For example, overestimation of the mineralisation coefficient of organic matter leading to overestimation of sub-root leaching could be compensated by overestimation of denitrification.

To understand why the PEI shows higher concentration and leaching values than SWAT, we need to examine their design individually:

- first, the PEI calculation is based on total nitrogen and not only mineral nitrogen. It therefore represents the leaching risk not for the current year but rather in the long term, through potentially mineralisable nitrogen. On the other hand, enrichment of the soil with 
organic matter (via livestock farming effluents, as in the area under study) directly results in higher PEI values, whereas in reality this enrichment does not systematically increase leaching. For situations without livestock farming, discrepancies between the PEI and the SWAT model are likely to be far smaller;

- one of the basic PEI assumptions is that gas exchanges are balanced (or almost). In the case under study, this hypothesis is probably not verifiable due to conditions favouring denitrification. The SWAT model simulates this denitrification;

- finally, the calculation period is implicitly different. With SWAT the mean nitrogen flows are usually calculated for a calendar year, from 1 January 2000 to 31 December 2001 and therefore represent a 365-day period. With PEI, leaching under the root zone is calculated for the period corresponding to both the crop and the intercrop period, a period that can be longer than 365 days (winter crop followed by spring crop) or shorter (the opposite).

\section{Risk spatialisation}

The Moine catchment area can be divided into 15 sub-catchment areas, whose outlets are defined by the measurement station or the water treatment station. To complete the test on the Pollution Emitting Indicator and the SWAT model, and to evaluate their efficiency for spatial differentiation, the pollution risks for each of the tributary catchment areas have been estimated and the results compared.

SWAT simulates sub-root leaching and concentration values with few differences between the catchment areas. The variation coefficients are in the order of $10 \%$ and the difference between the maximum and minimum is $10 \mathrm{kgN} / \mathrm{ha}$ for leaching and $11 \mathrm{mg} / \mathrm{l}$ for the concentration. The PEI also reveals this relative uniformity: the greatest difference between the sub-catchments is $20 \mathrm{~kg} \mathrm{~N} /$ ha for leaching and $8 \mathrm{mg} / 1$ for the concentration. The comparative analysis between Figures $2 \mathrm{~A}$ and $2 \mathrm{~B}$ shows some shifts from one class to another. However, the differences between these classes are very small. Under no circumstances can they be interpreted as corresponding to weak, medium and strong risks; all three classes correspond to "medium" risks.

The relative convergence of these spatialised results may seem surprising considering the differences of spatial resolution between SWAT and the PEI. In fact, the simulations with SWAT are based on smaller cells (HRU) than those used with the indicator (communes), and their description is more detailed: 
- soils are differentiated according to five parameters and according to their organisation in layers (PEI only takes the mean AWC into account for each commune);

- land use is understood through crop rotation (and not only through crops and intercrops as in the case of the PEI). Moreover, SWAT shows that the different types of rotation are the cause of a wide range of pollution risks (cf. Table 2).

The model and the indicator have also been submitted to a test of modified agricultural practice. In a simulated scenario of the $20 \%$ reduction of mineral fertilisation, there was comparable reduction of leaching and concentration: $10 \%$ with PEI and 7\% with SWAT. These results, which indicate that a reduction of fertilisers has only a small impact on the pollution risk, are convergent with many other studies (Lacroix et al., 2005; Vatn et al., 1999; Weaver et al., 1996). This impact is particularly weak when fertiliser inputs are close to the technical optimal quantities.

\section{DISCUSSION}

The comparison of results between the SWAT model and the PEI shows few differences in estimations of the drained water depth but values that sometimes double in the case of subroot leaching. This highlights the fact that water flows correspond to phenomena that are far less complex to apprehend than those governing nitrogen leaching. Due to the simplifications introduced by the PEI in calculations of nitrogen flows (particularly the hypothesis of balanced exchanges in the air and in the soil), the field of application of this indicator is limited. It is not appropriate for hydromorphic environments with a high level of denitrification.

We have highlighted the fact that discrepancies between leaching values are above all due to the fact that the PEI takes into account total nitrogen rather than only mineral nitrogen. This conceptual difference generates a difference in the temporal validity of the two methods. The PEI is an indicator of long-term risks. By contrast, owing to its daily time-step, the SWAT model is suitable for explaining phenomena and series of events that may account for climatic changes.

If we agree that there is a difference between the indicator and the model as regards the scope of the diagnosis (and therefore the leaching values), and that SWAT explains pollution processes more effectively, the following question arises. Can the PEI be used to classify situations correctly in relation to pollution risks? The indicator has shown its capacity to 
account for a reduction of fertilisation. It has produced leaching and concentration values for sub-catchment areas of the Moine that correspond to the low level of heterogeneity shown by SWAT. However, the specificity of the case to which it was applied (high level of homogeneity between the sub-catchment areas) seems to constitute a limit to the PEI reliability test for risk spatialisation.

Basically, the model and the indicator have the same goal: assessing the pollution risk. Their main difference lies in the tension between the finesse of the processes described and the operationality of the tool. These differences can be assessed from three angles:

- data used: the indicator draws on data that are easily accessible and not too numerous; the model usually requires numerous supplementary data;

- setting up: an indicator can be used by a non-specialised public; a model needs scientific expertise and far more training;

- expected results: an indicator points out a risk from a qualitative standpoint; a model aims at a quantitative estimation which may be validated or invalidated by measurements.

Both the indicator and the model are useful decision-making tools but the cost of applying them (work time and competencies) differs substantially. Thus, the choice of one or the other depends on the purpose of the evaluation:

- diagnosing areas of differing sizes. The indicator is appropriate for mapping imbalances at regional level. For more limited spaces, where in-depth knowledge of the soil and the processes involved is required, the model is more appropriate;

- identification of at-risk areas or practices. Theoretically, the PEI allows the identification of areas to watch. It can also be used to make assumptions on the origin of risks: the extent of spring crops, the presence or not of livestock breeding, the depth of the soil, etc. But only the model can prove that a particular agricultural practice is responsible, via the values simulated for the suspected cropping system;

- evaluating polluting emissions or their impact on the resource. The PEI is limited to the evaluation of nitrogen leaching under the root zone and consequently cannot be used to diagnose water resources. SWAT models nitrogen emissions in the soil as well as processes upstream (run-off, percolation, denitrification, etc.). It is therefore suited to the simulation of water and nitrogen transfers in groundwater and rivers, and can be used to predict isolated 
events such as concentration peaks. In this respect SWAT can serve to support water resource management on an ad hoc basis.

The comparison of the SWAT model and the Polluting Emission Indicator demonstrates that the choice of a method depends on the user profile - or more exactly, available competencies (scientific expertise, knowledge of the terrain) -, the time and means allocated to the evaluation, the extent of the study area, the time-step and, more generally, the purpose of the evaluation.

\section{ACKNOWLEDGMENT}

This work was partly supported by the French INRA programme PSDR (Pour et Sur le Développement Régional) and was originally presented at the INRA symposium "Territoires et Enjeux du Développement Régional”, Lyon, France, 9-11 March 2005.

\section{REFERENCES}

Aimon-Marie, F., Angevin, F. and Guichard, L. (2001) MERLIN, une méthode agronomique pour apprécier les risques de pollution diffuse par les nitrates d'origine agricole, Chambre d'agriculture Charente Maritime, INRA, ANDA, $27 \mathrm{p}$.

Aller, L., Bennet, T., Lehr, J.H., Petty, R.J. and Hackett, G. (1987) DRASTIC: a standardized system for evaluating groundwater pollution potentiel using hydrogeologic settings, US EPA Report 600/285/018, $163 \mathrm{p}$.

Arnold, J.G., Allen, P.M. and Bernhardt, G. (1993) 'A comprehensive surface-groundwater flow model', Journal of Hydrology, n 142, pp. 47-69.

Arnold, J.G., Srinivasan, R., Muttiah, R.S. and Williams, J.R. (1998) 'Large area hydrologic modeling and assessment, Part 1: Model Development', Journal of the American Water Resources Association, vol. $34, \mathrm{n}^{\circ}$ 1, pp. 73-90.

Arnold, J.G., Muttiah, R.S., Srinivasan, R. and Allen, P.M. (2000) 'Regional Estimation of base flow and groundwater recharge in the Upper Mississippi river basin', Journal of Hydrology, ${ }^{\circ} 227$, pp. 2041.

Auckenthaler, J., Huet, J. and Sebillotte, M. (1999) Diagnostic et maîtrise des risques de pollution agricole. Le cas des pollutions par les nitrates, Chambre régionale d'agriculture des Pays de la Loire, 27 p.

Benoît, M. (1992) 'Un indicateur des risques de pollution nommé BASCULE (Balance Azotée Spatialisée des systèmes de CULture de l'Exploitation)', Le Courrier de la Cellule Environnement INRA, vol. 18, pp. 23-28.

Berka, C., Schreier, H., and Hall, K. (2001) 'Linking water quality with agricultural intensification in a rural watershed', Water, Air, and Soil Pollution, n 127, pp. 389-401.

Beven, K.J. (1993) 'Prophecy, reality and uncertainty in distributed hydrological modelling', Advances in Water Resources, $\mathrm{n}^{\circ} 16, \mathrm{pp} .41-51$.

Béziers La Fosse, A., Canon, H., Crespo, J.C., Jézégou, A., Liu, Q., Nivet, D., Paepegaey, J.C., Picault, S., Rocheteau, E., Sauvage, R. and Viau, P.H. (2001) Etude des pratiques de fertilisation sur le bassin versant de la Moine', ESA, Angers. 
Bierkens, M.F.P., Finke, P.A. and De Willingen, P. (2000) Upscaling and Downscaling Methods for Environmental Research, Kluwer Academic Publishers, Dordrecht, Boston, 204 p.

Bordenave, P., Bouraoui, F., GascuelOdoux, C., Molenat, J. and Merot, P. (1999) 'Décalages temporels entre modifications des pratiques agricoles et diminution de nitrate dans les eaux superficielles.' In: Pollutions diffuses: du bassin versant au litoral, IFREMER ed., pp. 311-333.

Burkart, M., Kolpin, D. and James, D. (1999) 'Assessing groundwater vulnerability to agrichemical contamination in the Midwest US', Water Science and Technology, vol. 39, pp. 103-112.

Carrubba, L. (2000) 'Hydrologic Modeling at the Watershed Scale Using NPSM', Journal of the American Water Resources Association, vol. 36, n 6, pp. 1237-1246.

Chambres d'Agriculture, CEMAGREF, DDAF, DRAF-SRAE and Mission Eau Nitrates (1988) 'Bilan d'azote à l'exploitation', Ministère de l'Agriculture et de la Forêt, Secrétariat d'Etat chargé de l'Environnement, France, 35 p.

Crouzet, P., Le Gall, G. and Germain, C. (1999) Corine LC as basis layer to non point source emission assessment. Agricultural emissions comparison between the Loire $(F)$ and other european basin, Final Report for JRC ${ }^{\circ}$ 13432-97-11, IFEN/BETURE-CEREC, Orléans, France, $49 \mathrm{p}+$ annexes.

Euriat, A. and Tritz, F. (2002) Cartographie des sols et de leur vulnérabilité aux pollutions agricoles, bassin versant de la Moine, Mémoire de maîtrise de Sciences de la Terre et de l'Univers, Université Poincaré, Nancy, 63 p.

Haag, D. and Kaupenjohann, M. (2001) 'Landscape fate of nitrate fluxes and emissions in Central Europe. A critical review of concepts, data, and models for transport and retention', Agriculture, Ecosystems and Environment, $\mathrm{n}^{\circ}$ 86, pp. 1-21.

Hansen, J. (2000) 'Nitrogen balances in agriculture' Statistics in Focus, Theme 8 - 16/2000. EUROSTAT.

Lacroix, A., Beaudoin, N. and Makowski, D. (2005) 'Agricultural water nonpoint pollution control under uncertainty and climate variability', Ecological Economics, vol. 53, n¹, pp. 115-127.

Landreau, A., Mouvet, C., and Normand, B. (1999) 'Quelques aspects hydrologiques des transferts de solutés par infiltration vers les nappes : nitrates et phytosanitaires', La Houille Blanche, 1999, ${ }^{\circ}$ 5, pp. 81-86.

Le Gall, A., Legarto, J., Pfilimlin, A. and Cabaret, M.M. (2000) 'L'eau, l'azote et les systèmes d'élevage', Perspectives Agricoles, $\mathrm{n}^{\circ}$ 257, pp. 23-28.

Laurent, F. and Rossignol, J.P. (2004) 'Sensibilité d'un modèle agro-hydrologique à la cartographie des sols : test d'une méthode basée sur l'indice topographique et la lithologie', Etude et Gestion des Sols, 11(3), pp. 199-217.

Loague, K. and Corwin, D. (1998) 'Regionatscale assessment of non-point source groundwater contamination', Hydrological Processes, vol. 12, pp. 957-965.

Malczewski, J. (1999) 'Spatial Multicriteria Decision Analysis', In: Spatial Multicriteria Decision Making and Analysis, Thill, J.C. (ed.), Ashgate, Aldershot-Brookfield USA-Singapore-Sydeny, pp. 11-47.

Mary, B., Beaudoin, N. and Benoît, M. (1996) 'Prévention de la pollution nitrique à l'échelle du bassin d'alimentation en eau', in: Maîtrise de l'azote dans les agrosystèmes, INRA (ed.), Paris, pp. 289-312.

Mattikalli, N.M. and Richards, K.S. (1996) 'Estimation of surface water quality changes in response to land use change : Application of the export coefficient model using remote sensing and geographical information system', Journal of Environmental Management, vol. 48, n 3, pp. 263-282.

Merot, P. and Durand, P. (1997) 'Modelling the interactions between buffer zones and the catchment', In: Buffer zones : their processes and potential in water protection, Naycock, N.E., Burt, T.P., Goulding, K.W. and Pinay, G. (eds.), Quest Environment, Hertfordshire, pp. 208-217. 
Nash J. E., Suttcliffe J. V. (1970). 'River flow forecasting trough conceptual models. Part 1: A discussion of principles'. Journal of Hydrology, $\mathrm{n}^{\circ} 10$, pp. 282-290.

OCDE (1997) Environmental Indicators for Agriculture, vol. 1: Concepts and Framework, Publications Service, OCDE, Paris, 48 p.

OCDE (1999) Environmental Indicators for Agriculture, vol. 2: Issues and Design - The York Workshop, Publications Service, OCDE, Paris, 216 p.

OCDE (2001) Environmental Indicators for Agriculture, vol. 3: Methods and Results, Publications Service, OCDE, Paris, $416 \mathrm{p}$.

Parris, K. (1998) 'Agricultural nutrient balances as agri-environmental indicators: an OECD perspective', Environmental Pollution, vol. 102, n 1, Supplement 1, pp. 219-225.

Pau Vall, M. and Vidal, C. (1999) 'Nitrogen in Agriculture' In: Agriculture, Environment, Rural Development: Facts and Figures, Vidal C. et al. (eds), <http://europa.eu.int/comm/ dg06/envir/ report/en/ index.htm>.

Piorr, H.-P. (2003) 'Environmental policy, agri-environmental indicators and landscape indicators', Agriculture, Ecosystems \& Environment, vol. 98, n 1-3, pp. 17-33.

Pullar, D. and Springer, D. (2000) 'Towards integrating GIS and catchment models', Environmental Modelling and Software, $\mathrm{n}^{\circ}$ 15, pp. 451-459.

Rapion, P. and Bordenave, P. (2001) 'Pratiques agricoles et pollutions azotées diffuses des eaux de surface : exemples d'évaluation d'impact sur trois bassins versants d'élevage intensif', Actes du colloque Hydrosystèmes, Paysages, Territoires, Lille, 6-8 septembre 2001, http://www.univlille1.fr/geographie/labo/gma.htm.

Refsgaard, J.C., Thorsen, M., Jensen, J.B., Kleeschlute, S. and Hansen, S. (1999) 'Large scale modelling of groundwater contamination for nitrate leaching', Journal of Hydrology, n ${ }^{\circ} 221$, pp. 117140.

Réménieras, G. (1960) L'hydrologie de l'ingénieur, Eyrolles, Paris, 413 p.

Ruelland, D. (2004) 'SENEQUE, logiciel SIG de modélisation prospective de la qualité de l'eau', Revue Internationale de Géomatique, vol. 14, n 1, pp. 97-117.

Ruelland, D., Laurent, F. and Trebouet, A. (2004) 'Spatialisation de successions culturales à partir d'images HRV(XS) de SPOT pour une intégration dans un modèle agro-hydrologique', Teledetection, vol. $4, \mathrm{n}^{\circ} 3$, p. 231-250.

Santhi, C., Arnold, J.G., Williams, J.R., Dugas, W.A., Srinivasan, R. and Hauck, L.M. (2001) 'Validation of the SWAT model on a large river basin with point and nonpoint sources', Journal of the American Water Resources Association, vol. 37, n 5, pp. 1169-1189.

Schroder, J.J., Scholefield, D., Cabral, F. and Hofman, G. (2004) 'The effects of nutrient losses from agriculture on ground and surface water quality: the position of science in developing indicators for regulation', Environmental Science \& Policy, vol. 7, n 1, pp. 15-23.

Simon, J.-C. and Le Corre, L. (1992) 'Le bilan apparent de l'azote à l'échelle de l'exploitation agricole : méthodologie, exemples de résultats', Fourrages, n 129, pp. 79-94.

Srinivasan, R., Ramanarayanan, T.S., Arnold, J.G. and Bednarz, S.T. (1998) 'Large area hydrologic modeling and assessment, Part 1: Model Application', Journal of the American Water Resources Association, vol. 34, $\mathrm{n}^{\circ}$ 1, pp. 91-101.

Tripathi, M.P., Panda, R.K. and Raghuwanshi, N.S. (2003) 'Identification and priorisation of critical sub-watersheds for soil conservation management using the SWAT model', Biosystems Engineering, vol. 85, n³, p. 365-379. 
Vaché, K., Eilers, J. and Santelmann, M. (2002) 'Water Quality Modeling of Alternative Agricultural Scenarios in the US Corn Belt', Journal of the American Water Resources Association, vol. 38, $\mathrm{n}^{\circ} 3$, pp. 773-787.

Van der Werf, H.M.G. and Petit, J. (2002) 'Evaluation of the environmental impact of agriculture at the farm level: a comparison and analysis of 12 indicator-based methods', Agriculture, Ecosystems \& Environment, vol. 93, n 1-3, pp. 131-145.

Vatn, A., Bakken, L., Botterweg, P. and Romstad, E. (1999) 'ECECMOD: an interdisciplinary modelling system for analyzing nutrient and soil losses from agriculture', Ecological Economics, vol. 30, $\mathrm{n}^{\circ} 2$, pp. 189-206.

Vervier, P., Pinheiro, A., Fabre, A., Pinay, G. and Fustec, E. (1999) 'Spatial changes in the modalities of $\mathrm{N}$ and $\mathrm{P}$ inputs in a rural river network', Water research (Oxford), vol. 33, $\mathrm{n}^{\circ}$ 1, pp. 95-104.

Vidal, C. (1995) Logiciel de calcul du bilan de l'azote à l'échelle cantonale: Ministère de l'Agriculture, Service Central des Enquêtes et Etudes Statistiques, 24 p.

Vrba, J. and Zoporozec, A. (1994) Guidebook on mapping groundwater vulnerability, International Contribution for Hydrogeology, Vol. 16, International Association of Hydrogeologists, Hannover, Germany, $131 \mathrm{p}$.

Weaver, R.D., Harper, J.K. and Gillmeister, W.J. (1996) 'Efficacy of standards vs. incentives for managing the environmental impacts of agriculture', Journal of Environmental Management, vol. 46, $\mathrm{n}^{\circ} 2$, pp. 173-188.

Wickham, J.D., Riiters, K.H., O'Neill, R.V., Reckhow, K.H., Wade, T.G. and Jones, K.B. (2000) 'Land Cover as a Framework for Assessing Risk of Water Pollution', Journal of the American Water Resources Association, vol. 36, n 6, pp. 1417-1422.

Worrall, F. and Burt, T.P. (1999) 'The impact of land-use change on water quality at the catchment scale : the use of export coefficient and structural tools', Journal of Hydrology, ${ }^{\circ} 221$, pp. 75-90. 
Table 1. Comparison of input datas of the two methods

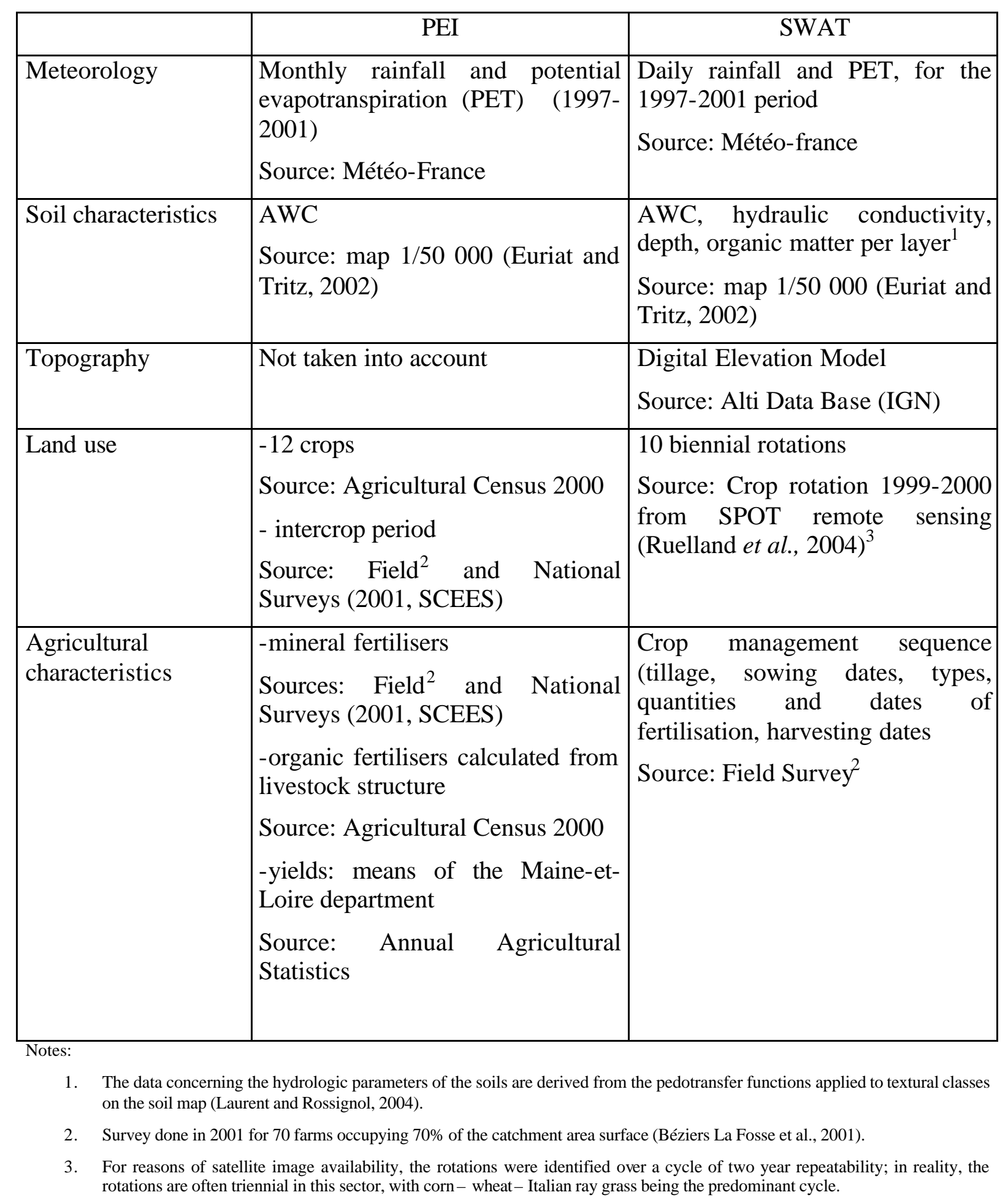




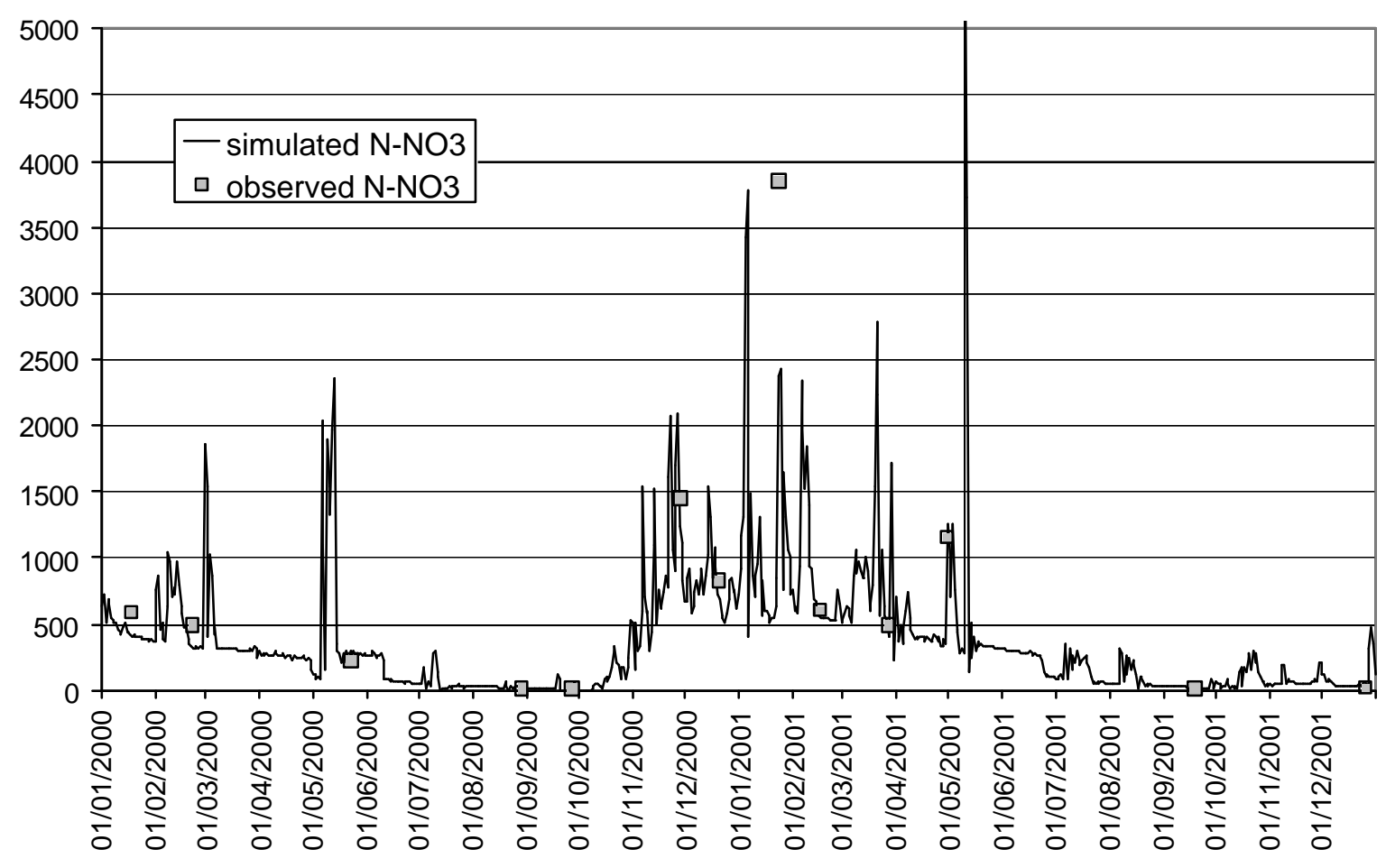

Figure 1: Nitrate flows (kgN-NO3/day) in the River Moine from 2000 to 2001 
Figure 2. Assessment of nitrogen leaching $\left(\mathrm{kgN} / \mathrm{ha}^{-1} \cdot \mathrm{an}^{-1}\right)$ for the sub-catchment areas of the Moine for 1997-2001 period.

2A. with the SWAT model

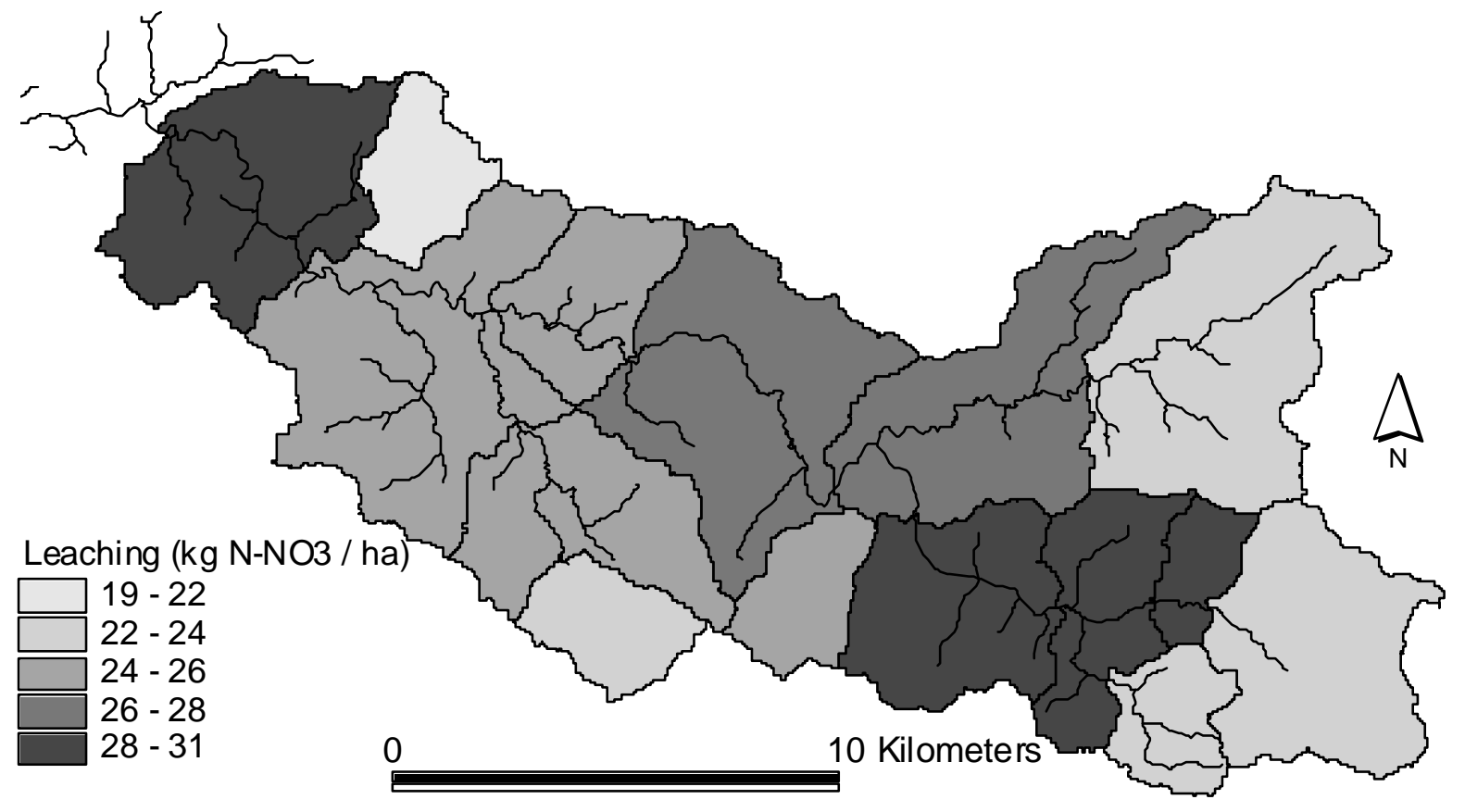

2B. with the Polluting Emission Indicator

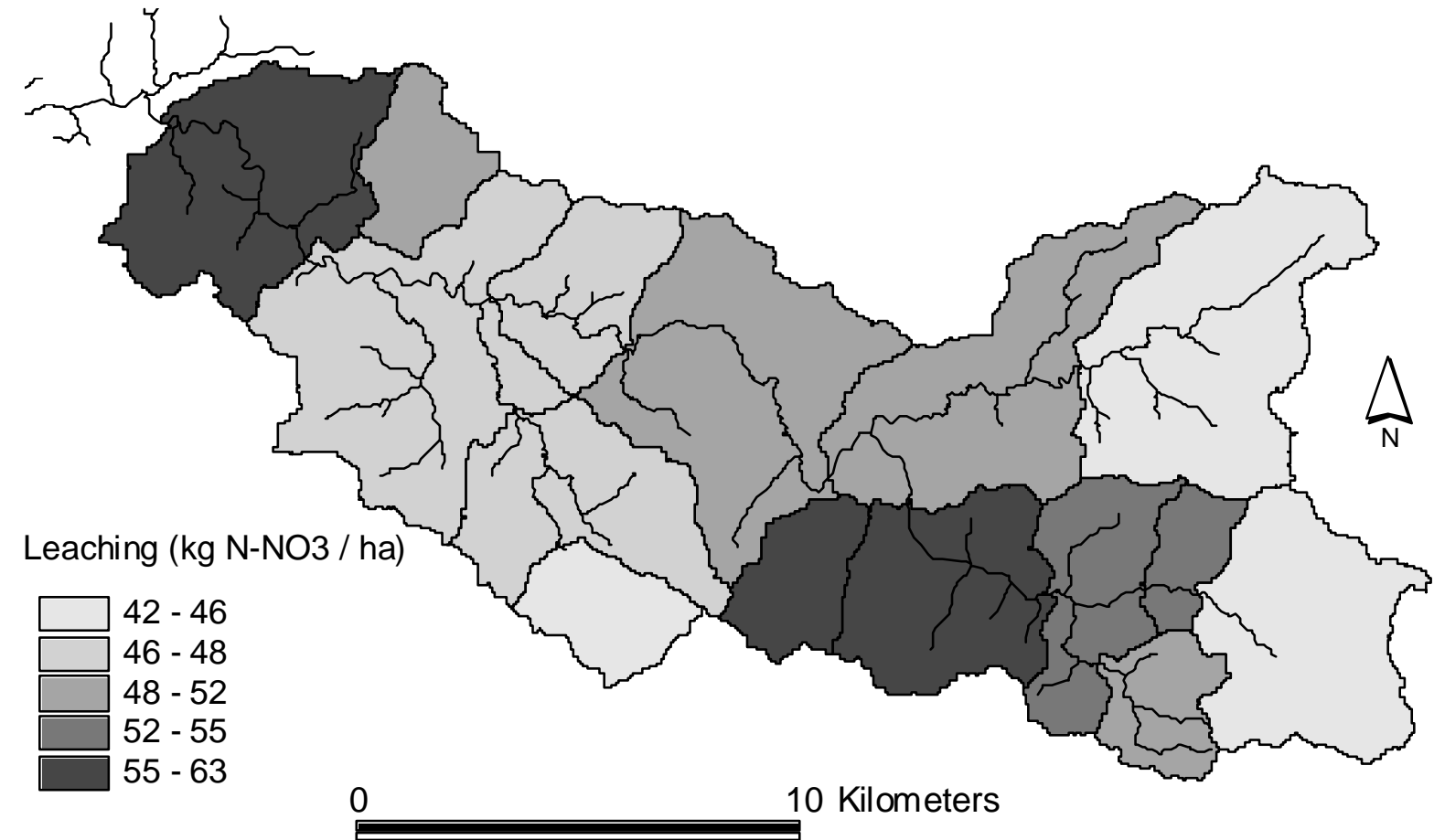


Table 2. Leaching and sub-root concentration according to crop rotation (SWAT simulation, 1997-2001)

\begin{tabular}{|l|c|c|}
\hline Types of modelled rotation & Leaching $\left(\mathrm{kgN}-\mathrm{NO}_{3} / \mathrm{ha} / \mathrm{an}\right)$ & $\begin{array}{c}\text { Concentration }\left(\mathrm{mgNO}_{3} / 1\right) \text { of } \\
\text { the drained water below the } \\
\text { root zone }\end{array}$ \\
\hline Permanent grass & 21 & 32 \\
\hline Temporary grass & 22 & 33 \\
\hline Corn/IRG & 23 & 34 \\
\hline Wheat/wheat & 28 & 31 \\
\hline Wheat/IRG & 34 & 44 \\
\hline Wheat/corn & 38 & 74 \\
\hline Corn/Corn & 52 & 46 \\
\hline
\end{tabular}

Note $:$ RGI $=$ Ray Grass Italien 